\title{
Retención voluntaria como medio para levantar la prohibición de ausentarse del país
}

\author{
Voluntary retention as a means of lifting the ban on \\ absences from the country
}

\author{
Estefanía Samaniego Valencia \\ Investigadora jurídica independiente \\ Ciudad: Quito \\ País: Ecuador
}

Artículo original (investigación)

RFJ, No. 7, 2020, pp. 320-334, ISSN 2588-0837

RESUMEN: El presente trabajo se centra en analizar si la retención voluntaria a prorrata del sueldo del alimentante es un medio apto para levantar provisionalmente la medida cautelar de prohibición de ausentarse del país. Para el desarrollo de este se basará en el tipo de investigación documental, descriptivo y explicativo, aplicando como métodos de investigación el deductivo e inductivo. Esta idea se plantea con el fin de que los alimentantes que realicen pagos constantes de la pensión de alimentos (acogiéndose a una retención previa), pese a mantener cuotas devengadas, puedan solicitar el levantamiento de la medida cautelar impuesta. Por todo lo expuesto, se pretende que la idea planteada de la retención voluntaria sea una opción que beneficie tanto al alimentario como al alimentante, para que ambos sujetos de la obligación puedan gozar de sus derechos sin privar a la otra parte del ejercicio pleno de los mismos.

PALABRAS CLAVES: Retención, salario, derechos del niño, crecimiento económico.

ABTRACT: This paper aims to analyze whether the voluntary withholding of the breadwinner's salary is a suitable means of provisionally lifting the precautionary measure prohibiting absences from the country. Its development will be based on 
the type of documentary, descriptive and explanatory research, using the deductive and inductive as research methods. This idea involves that those who make regular maintenance payments (subject to prior retention) and, despite making regular contributions, can request the lifting of the precautionary measure imposed. The idea of voluntary retention looks to be an option and introduce some benefits (both the food and the food-stuffer). For instance, both parties to the obligation can enjoy their rights without depriving them of the full exercise of those rights.

KEY WORDS: Retention, salary, rights of the child, economic growth.

\section{INTRODUCCIÓN}

De acuerdo a la Convención Interamericana sobre obligaciones alimentarias ámbito de aplicación (1989) “Los alimentos deben ser proporcionales tanto a la necesidad del alimentario, como a la capacidad económica del alimentante"; es por eso, que para establecer el monto que el alimentante debe otorgar al alimentario se considera el salario que perciba, el número de hijos que tenga y sus respectivas edades. De acuerdo a estos factores, para el cálculo del monto a pagar por concepto de pensión alimenticia, el Consejo de la Judicatura diseñó una tabla ${ }^{1}$ que cuenta con seis niveles que se ajustan a los ingresos económicos del alimentante.

Pese a esto, existen casos en que, al momento de fijar la pensión de alimentos, esta resulta ser demasiada en relación a los recursos económicos del alimentante para cubrir y cumplir con su obligación, puesto que solo analizan el valor neto de los ingresos que reciben, sin calcular los demás gastos fuera que puedan tener, como el alquiler de una casa o pago de estudios. En muchos casos a la parte demandante no le interesa los gastos

1 Las pensiones establecidas en la tabla serán automáticamente indexadas dentro de los quince primeros días del mes de enero de cada año, considerando además el índice de inflación publicado por el Instituto Nacional de Estadísticas y Censos, (INEC) en el mes de diciembre del año inmediato anterior y en el mismo porcentaje en que se aumente la remuneración básica unificada del trabajador en general. 
externos que el alimentante mantenga, a tal punto de rechazar toda clase de acuerdo que incite a una rebaja de la pensión, llegando a acumular con el pasar del tiempo cantidades difíciles de liquidar.

Es por ello, que ante la necesidad de que se dé cumplimiento al pago de la pensión de alimentos, se fija la imposición de diversas medidas cautelares, entre las más comunes la privación de libertad y la prohibición de salida del país. Si bien es cierto, la imposición de medidas cautelares de manera general es para asegurar el resultado de una acción; de manera concreta en cuestión de alimentos sería para el cumplimiento del pago de la pensión alimenticia. Sin embargo, a veces estas medidas no contribuyen a que el alimentante pague lo adeudado.

Puesto que, en la mayoría de los casos, no es la voluntad del alimentante de incumplir con sus obligaciones familiares, sino que dicho incumplimiento se suele dar porque al momento de fijar la cantidad por concepto de alimentos, no se toma en consideración los egresos que sostenga, haciendo referencia a los gastos producto de los miembros de su familia que estén bajo su cuidado y a la subsistencia del propio alimentante; razón por la cual, grandes cantidades de alimentantes acumulan elevados valores a cancelar y se encuentran atrasados en los pagos de pensiones alimenticias.

En vista de que con el pasar del tiempo la situación económica de un sujeto puede cambiar; planteando un caso hipotético, si el alimentante está cumpliendo con el pago de la pensión de alimentos pero adeuda pensiones pasadas $^{2}$ (en vista de que

2 El derecho a alimentos es tan propio del ser humano que va de la mano con las garantías de proporcionar los recursos necesarios para cubrir sus necesidades básicas, es por eso que no se pueden transferir ni renunciar a ellos, pero la legislación ecuatoriana plantea dos casos como excepciones aplicables a esta regla, puesto que establece que si se podrán renunciar o compensarse cuando se traten de pensiones alimenticias atrasadas y se podrá transmitir por causa de muerte, venderse o cederse, el derecho de demandarlas, sin perjuicio de la prescripción que le competa al deudor, en este caso al alimentante.

Parece contradictorio, pero hay que aclarar que lo que no se puede transmitir por causa de muerte es el "derecho de pedir alimentos" más no, el derecho de demandar las "pensiones atrasadas"; los derechos conferidos 
en el momento que se fijaron no contaba con los medios suficientes para cubrirlas), ante el cumplimiento del alimentante; se pretende plantear un acuerdo, el cual consiste en una solicitud para descontar del sueldo, la pensión de alimentos y; ante la retención voluntaria a prorrata del sueldo del alimentante, se pueda levantar provisionalmente la medida cautelar de prohibición de salida del país que recae sobre él.

En el presente trabajo de investigación se analizará si la retención voluntaria a prorrata del sueldo que percibe el alimentante, es un medio apto para sustituir la medida cautelar de prohibición de salida del país; planteándolo como una medida alterna que posibilite el levantamiento provisional de la medida cautelar. Cabe recalcar que, aunque se mantenga cuotas alimenticias pendientes de pago, no es motivo para imposibilitar al alimentante a acogerse a la propuesta planteada, en vista de que lo que se busca es el beneficio de ambos sujetos de la obligación.

\section{MEDIDAS CAUTELARES EN ALIMENTOS}

Las medidas cautelares tienen su origen en Roma (753 a.C.). En Ecuador por primera vez hace su aparición en la Constitución Política de 1998 como medidas urgentes destinadas a evitar la comisión de actos ilegítimos de una autoridad o remediar las consecuencias de estos, con el fin de que no incurran en posibles violaciones que puedan causar daño grave a los derechos establecidos en la norma. (Vaca, 2017)

Estas medidas que se imponen al alimentante por el incumplimiento del pago de la obligación de prestar alimentos, es con la finalidad de reivindicar al alimentario por el perjuicio ocasionado; puesto que, al momento de no cumplir con la obligación alimenticia, el alimentario no tendría como satisfacer o cubrir sus necesidades básicas que generalmente comprende alimentación, educación, salud y las demás que abarcan

por la ley podrán renunciarse siempre que no esté prohibida su renuncia y que solo se mire al interés del renunciante, y en efecto la ley determina que las pensiones atrasadas si se pueden renunciar o compensar, esto se lo puede encontrar en el Art. 364 del Código Civil (2005, Libro I). 
tanto la ley como la vida misma, afectando de cierto modo su desarrollo integral.

En la legislación ecuatoriana tanto en la Constitución de la República del Ecuador como en la Ley Orgánica de Garantías Jurisdiccionales y Control Constitucional, establece que las medidas cautelares se pueden ordenar para evitar o hacer cesar alguna amenaza o violación de los derechos consagrados en la Constitución o instrumentos internacionales sobre derechos humanos.

Por otro lado, Medina (2010) plantea que:

El sistema jurídico se sirve de la punición directa para proteger el derecho que tienen los menores $\mathrm{y}$ las personas desvalidas a obtener lo necesario para su subsistencia, no tanto para sancionar el incumplimiento de la obligación en sí misma, sino el atentado que se comete contra esa persona, que no es menos lesivo que muchos ataques contra la integridad del sujeto. (p. 607)

Es por ello, que las medidas cautelares pueden ser activadas cuando ocurren tanto amenazas como vulneraciones o violaciones de los derechos constitucionales, sin embargo, los efectos en uno u otro caso son distintos. En el primer supuesto, es decir en caso de que concurran las amenazas, el objetivo es prevenir una posible vulneración de los derechos, evitando que sucedan los hechos que se consideran atentatorios a derechos; en tanto que el segundo supuesto, es decir en el caso de vulneraciones o violaciones a derechos constitucionales, el objeto es cesar dicha transgresión. (Corte Constitucional, 2012)

Las medidas cautelares en su más simple acepción terminológica significan prevención, disposición; prevención a su vez, equivale a conjunto de precauciones y medidas tomadas para evitar un riesgo. En el campo jurídico, se entiende como tales a aquellas medidas que el legislador ha dictado con el objeto de que la parte vencedora no quede burlada en su derecho. En el campo procesal civil las medidas cautelares constituyen una excepcional institución de garantía 
del cumplimiento de la eventual sentencia que se dicte dentro de un proceso, sin distinguir su naturaleza, ya se trate de un declarativo, liquidatario, ejecutivo, etc. (Calderón, 2010, p. 100)

En resumidas palabras se puede decir que estas medidas se utilizan para hacer efectivo el ejercicio de los derechos que contempla el estatuto supremo de un Estado, o a su vez las normas internacionales de derechos humanos que rigen a los ciudadanos, para prevenir que el derecho otorgado sea vulnerado o violado.

Si bien es cierto, la legislación ecuatoriana fija como medida coercitiva al apremio, el cual se divide en personal y real, pero en cuestión de alimentos se podría decir que se inclina más la imposición del apremio personal, recayendo sobre la prohibición de ausentarse del país y la privación de libertad.

Estas medidas de apremio, tanto las que recaen sobre el patrimonio como las que se aplican sobre la persona, buscan el mismo fin; es decir, pretenden garantizar el derecho a la vida digna y protección integral de niñas, niños y adolescentes a través del pago de la prestación, sin embargo vemos que las mentadas medidas violentan el principio de igualdad y no discriminación previsto en el numeral 2 del artículo 11 de la Constitución de la República, que entre otras situaciones, prohíbe la discriminación por razones socio-económicas, ya que el alimentante que posea patrimonio suficiente como bienes muebles e inmuebles y otros activos que garanticen el pago de la adeudado se le aplicará el apremio real y no el apremio personal mientras que el alimentante de escasos recursos e ingresos económicos que no pueda garantizar el cumplimiento de la deuda con su patrimonio se le aplicara directamente la privación de la libertad, al ser la única medida aplicable; es decir, la norma favorece a los que poseen bienes y es gravosa para el que no los tiene. En dicho contexto, la regulación vigente sobre apremio no solo que no es idónea, sino que es lesiva de derechos al limitarlos. (Corte Constitucional, 2017) 
La legislación ecuatoriana no tiene una amplia información sobre la medida de prohibición de ausentarse del país; es concreta al establecer, cuando se puede aplicar y cuando puede cesar o revocarse la medida. Se podría definir como una medida que es utilizada para prevenir el incumplimiento del alimentante evitando que salga del país para que no eluda su responsabilidad. Esta medida se impone previa solicitud al Juez, quien dispondrá el impedimento de salida del país, notificando a los organismos y autoridades responsables para que se registre la alerta en el Sistema de Control Migratorio del Ministerio del Interior.

En respuesta de consulta a Corte Nacional, referente a como ordenarse la prohibición de salida del país, se llegó a la conclusión que al encontrarse vigente al art. 25 de la Ley Reformatoria al Código de la Niñez y Adolescencia y conforme a la Resolución de la Corte Constitucional, la prohibición de la salida del país constituye una medida cautelar que puede ordenarse desde la calificación de la demanda hasta antes de la audiencia única.

Por otro lado, el articulo Innumerado 25 del Código Orgánico de Niñez y Adolescencia reformado y publicado en el R.O. 643S, 28VII2009 prescribe que "a petición de parte, en la primera providencia, el juez decretará sin notificación previa, la prohibición de ausentarse del territorio nacional, la que se comunicará de inmediato a la Dirección Nacional de Migración.”. Es decir que cuando la parte actora presenta la demanda -formulario único de pensión alimenticia- y solicita la aplicación de esta medida cautelar, el juez está en la obligación de ordenar esta medida -en el auto de calificación de la demanda- por así estar establecido en la ley. (Ab. Quishpe, 2018)

Actualmente se puede consultar a través de página web del Ministerio de Gobierno, si una persona consta con prohibición de salida del país, solo se requiere el número de cédula y su fecha de nacimiento para obtener dicha información. Para realizar el trámite se debe ingresar a la página web del Ministerio de Gobierno y presionar el botón "Ir al trámite en línea”. 
De conformidad con el artículo 137 del Código Orgánico General de Procesos, referente al apremio personal en materia de alimentos, establece que en el caso que el alimentante demostrare de manera justificada su incapacidad de cumplir con sus obligaciones, la o el juzgador aprobará una propuesta del alimentante en torno a su compromiso de pago para cancelar lo adeudado, precautelando siempre los derechos del alimentario.

Dicho esto, se podría considerar a la retención voluntaria como un compromiso de pago y con el cumplimiento constante de la obligación (a partir de la retención), se podría demostrar que ya no hay necesidad de mantener la medida cautelar de prohibición de ausentarse del país, puesto que la obligación se está cumpliendo y ya no habría derecho vulnerado. Claro está que antes de solicitar el levantamiento de la medida cautelar, el alimentante deberá demostrar que percibe un ingreso mensual fijo y constante que le permitirá cubrir con la pensión fijada por el Juez.

\section{CESACIÓN DE APREMIOS}

Hay que tener en cuenta que existen personas que tienen los recursos para responder a la obligación impuesta, pero prefieren no hacerlo y otras que en realidad no tienen los recursos económicos suficientes para cumplir con la obligación y pese a ello buscan la manera para evitar las consecuencias que conllevan el no pago de la pensión alimenticia.

Si bien es cierto la legislación ecuatoriana determina que para el cese de los apremios haciendo referencia a la prohibición de salida del país y al apremio personal, se requiere o bien que se cumpla con el pago total de la obligación o que se rinda caución suficiente que respalde la misma; en cambio para que cese los demás apremios como la prohibición de enajenar o las inhabilidades como no poder ocupar cargo público, se deberá realizar el pago total de la deuda incluido los interés generados por mora.

En la Resolución 080-2016, emitida por el Consejo de la Judicatura establece que para el cese de la medida cautelar de 
prohibición de salida del país, la caución ${ }^{3}$ rendida deberá cubrir por lo menos el tiempo que el obligado se va a ausentar calculando sobre la base de la última pensión; sin hacer mención sobre las pensiones devengadas. Por lo que planteando un caso hipotético tenemos lo siguiente: se conoce que las pensiones alimenticias se pagan mensualmente; suponiendo que el alimentante se quiera ausentar una semana por motivos de vacaciones o trabajo, $\mathrm{y}$ tiene una pensión mínima fijada, percibiendo un sueldo básico; tranquilamente el sueldo venidero seria respaldo para cubrir la obligación, siendo la retención voluntaria un medio apto para levantar provisionalmente la prohibición de salida del país.

De acuerdo con la Resolución 080-2016, hay varios tipos de caución, entre la clasificación existente, se entienden como caución real a aquellas que recaen sobre el patrimonio que son:

a) Hipotecaria: necesita constar con el certificado del Registrador de la Propiedad donde se encuentre que el bien inmueble está libre de gravamen y el catastro municipal.

b) Prendaria: se deberá acompañar con los documentos que acrediten que el bien dado en prenda esté libre de gravámenes o prohibiciones que puedan afectar al momento de la inscripción.

c) Pecuniaria: es cuando el juez recepta el pago del valor acordado realizado por el alimentante ya sea de cualquier forma que estipula la ley este puede ser en efectivo; por cheque certificado, que es cuando una entidad financiera avala que la persona (alimentante) cuenta con los fondos necesarios para cubrir la obligación; o, por carta de garantía, que es cuando la institución bancaria responde ante un tercero en este caso al beneficiario de la prestación alimenticia por cuenta del alimentante por un tiempo determinado.

d) Por póliza de seguro de fianza: se trata de un acuerdo suscrito por tres partes; una de las partes es la afianzadora, que vendría a ser la compañía de seguros

3 En concordancia con el Art. 31 del Código Civil (2005) establece que "caución significa generalmente cualquiera obligación que se contrae para la seguridad de otra obligación propia o ajena”. 
que responde por el afianzado y la tercera parte es el asegurado que viene a ser el beneficiario y en este caso le corresponde ser a la judicatura que ordeno la medida. El incumplimiento de la obligación garantiza el seguro de fianza, es decir que si el alimentante como afianzado incumple la obligación de prestar alimentos la afianzadora responde por el ante el beneficiario.

En cuanto a la caución personal como su nombre hace alusión recae sobre las personas en este caso comprende:

a) Garante o fiador: es aquel que se hace responsable y se compromete a responder por otra persona, a su vez deberá presentar documentos que validen que es propietario de bienes que pueden cubrir el monto de la caución, dichos bienes que pasan a ser objeto de caución no podrán ser inscritos con nuevos gravámenes.

\section{VIABILIDAD DE LA RETENCIÓN}

La retención "tendrá lugar solo cuando exista una causa lo suficientemente relevante para ello; es decir, en aquellos casos en que se hayan agotado otras vías de negociación o si el incumplimiento del pago pone en riesgo los derechos fundamentales de otras personas" (Anónimo, 2018). En cuestión de alimentos la retención se aplica al trabajador (alimentante) en caso de que mantenga pensiones alimenticias impagas y se niegue a cumplir con su deber de prestar alimentos, que cubran las necesidades básicas del niño, niña y adolescente.

Por otro lado, la retención judicial por pensión alimenticia es una medida que puede ser solicitada al Tribunal de Familia y que tiene por objeto evitar futuros incumplimientos por parte del alimentante. En la retención judicial, el Tribunal oficia al empleador para que este retenga del sueldo del alimentante las sumas de dinero que correspondan a la pensión de alimentos decretada (Acosta, 2014). 
Una pregunta clave que se debe plantear para continuar con la investigación es si, ¿Es procedente la retención voluntaria a prorrata del sueldo del alimentante?; Si bien es cierto conforme a la Constitución, la remuneración se caracteriza por ser inembargable, se debe dar en los plazos convenidos y no podrá ser disminuido a menos que la ley lo mande o el trabajador lo autorice; lo que deja carta abierta a la voluntad del alimentante, sumándole a esto la excepción aplicable a la inembargabilidad ${ }^{4}$ de la remuneración frente a los casos de pensiones alimenticias; se llega a la conclusión que si se puede dar la retención del sueldo, salario u otra percepción que el alimentante reciba, siempre y cuando consienta en ello o en su defecto la ley así lo determine.

Se podría decir que la retención voluntaria sería una medida que beneficiaría tanto al obligado a prestar alimentos como al beneficiario de recibirlos; de tal modo que el alimentario obtiene el pago de su cuota alimenticia y el alimentante puede despreocuparse de incurrir en el incumplimiento de la obligación, en vista de que la pensión de alimentos será descontada de su rol de pagos y pagada directamente al beneficiario de la obligación.

Una vez que el alimentante se acoge a la retención a prorrata de su sueldo de manera voluntaria, la imposición de la medida de prohibición de salida del país deja de tener sentido; ¿Por qué? Porque si bien es cierto el objeto de la medida cautelar es asegurar de que se cumpla la obligación y al aplicar la retención, se comenzaría a efectuar el descuento vía rol y con eso se aseguraría el pago de la cuota alimenticia. En vista de que se estaría dando cumplimiento a la obligación, ya no habría necesidad de mantener la medida cautelar impuesta.

$4 \quad$ El Código Civil (2005) en su art. 1634 señala que "Tanto los sueldos como las remuneraciones a que se refiere este ordinal son embargables para el pago de alimentos debidos por ley". El art. 91 del Código del Trabajo (2005) establece que "la remuneración del trabajo será inembargable, salvo para el pago de pensiones alimenticias". 


\section{CONCLUSIÓN}

En cierto grado es necesaria la imposición de la medida cautelar de prohibición de salida del país, de conformidad con el Pacto Internacional de Derechos Civiles y Políticos, habrá restricciones aplicables a la libre circulación cuando lo que se pretende es proteger los derechos de terceros. Enfocándose en materia de alimentos, la restricción sería para la protección al derecho de alimentos que por ley le corresponde recibir al alimentario, prohibiéndole al alimentante ausentarse del país para que dé cumplimiento con la obligación.

Cabe recalcar que a veces se dificulta el cumplimiento de la obligación en su totalidad mayormente por dos factores; primero, porque la pensión corre desde que se interpone la demanda llegando a acumular cantidades exuberantes que se tornan difíciles de cancelar, y el segundo que va de la mano, es la falta de recursos económicos suficientes del alimentante, lo que complica el acogerse al levantamiento de una medida cautelar.

En nuestra legislación establece a la prohibición de salida del país como medida cautelar para asegurar el cumplimiento de una obligación. Como se mencionó en el desarrollo del presente trabajo, existen varias formas para que cese la medida cautelar de prohibición de salida del país que recae sobre el alimentante; pero el problema para acogerse a una de ellas es la falta de recursos económicos que impide el pago completo de la obligación, rendir garantía suficiente o encontrar a alguien que quiera figurar como garante.

Es por esta razón que en caso de que la situación económica del alimentante mejore, se busca implementar como una alternativa, que ante el pago constante de la obligación alimentaria o ante una solicitud de retención voluntaria a prorrata del sueldo por parte del alimentante, se levante de manera provisional la medida de prohibición de salida del país en virtud de que se está cumpliendo con la obligación. 
Esta alternativa también puede ser acogida por el alimentante que tenga existente una retención judicial, sin importar que aún mantenga pensiones alimenticias pasadas, vigentes de pago, siempre y cuando se demuestre un cumplimiento constante y periódico.

Un caso por la cual se plantea esta propuesta es que a veces el alimentario se le presenta situaciones como un viaje de trabajo o vacaciones; entonces en el hipotético caso que le toque ausentarse del país por una semana, lo que se pretende es que al acogerse a la propuesta de la retención voluntaria, su sueldo futuro sirva como respaldo para que pueda salir del país; puesto que a partir de la retención, el empleador sería el encargado de efectuar el descuento vía rol por concepto de alimentos y de acreditar los valores correspondientes en la cuenta del beneficiario.

Por todo lo expuesto se pretende que se acoja un formulario de fácil acceso que conste en la página web del Consejo de la Judicatura, para solicitar la retención voluntaria a prorrata del sueldo del alimentante para levantar provisionalmente la medida cautelar de ausentarse del país que recae sobre él, en virtud del cumplimiento del alimentante frente a la obligación y de los principios de celeridad y economía procesal. Para cerciorarse del respectivo cumplimiento se puede anexar al formulario, el rol de pagos donde constan los descuentos o a su vez el detalle de la tarjeta del $\mathrm{SUPA}^{5}$ asignada a su juicio de alimentos, para verificar las pensiones acreditadas.

\section{REFERENCIAS BIBLIOGRAFICAS}

Ab. Quishpe, J. (2018). La prohibición de salida del país en materia de alimentos. Cruz Ponce \& Asociados. Recuperado de: https://n9.cl/son27

Acosta, A. (2014). Instructivo para la carga masiva de retenciones judiciales. (M. d. Finanzas, Ed.) Recuperado de: https:// n9.cl/ozy0

5 Es el Sistema Único de Pensiones Alimenticias del Consejo de la Judicatura que garantiza el adecuado y oportuno proceso de recaudación y pago de pensiones alimenticias, a favor de los usuarios de la administración de justicia.

Revista de la Facultad de Jurisprudencia RFJ No.7 Junio 2020 pp. 320-334 332 
Anónimo. (2018). Retos para ser Directivo. [Blog]. Recuperado de: https://retos-directivos.eae.es/que-es-la-retencion-judicial-en-nomina-de-un-trabajador/

Asamblea Nacional del Ecuador. Código Orgánico General de Procesos. [Cod.]. (22 de mayo 2015). R. O. 506 de 22 de mayo de 2015. Recuperado de: https://n9.cl/0olam

Calderón, N. (2010). Diseño Criminal: El Ecuador a partir de las reformas del Código Penal y Código de Procedimiento Penal. Revista jurídica online, (p. 100).

Congreso Nacional del Ecuador. Código Civil. [Cod. 10]. (2005). R. O. 46 de 24 de junio de 2005.

Congreso Nacional del Ecuador. Código del Trabajo. [Cod. 17]. (2005). R. O. 167 de 16-dic.-2005.

Consejo de la Judicatura. Resolución 080-2016. (2016). Instructivo sobre cauciones en juicios de alimentos. Recuperado de: http://www.funcionjudicial.gob.ec/www/pdf/resoluciones/080-2016.pdf

Constitución de la República del Ecuador [Const.]. (2008). 2da Ed. CEP.

Convención Americana de Derechos Humanos. (22 de noviembre de 1969). Pacto de San José de Costa Rica. Recuperado de: https://n9.cl/jpyc

Corte Constitucional del Ecuador. (10 de mayo de 2017) Sentencia No. 012-17-SIN-CC.

Corte Constitucional del Ecuador. (30 de mayo de 2013). Sentencia No. 034-13-SCN-CC.

Corte Nacional de Justicia. (24 de abril de 2018). Absolución de Consultas.

Medina Pabón Juan Enrique (2010). “Derecho civil. Derecho en familia, segunda edición”. Ed. Universidad del Rosario. P. 571, 607 
Pacto Internacional de Derechos Civiles y Políticos (16 diciembre 1966). Recuperado de: https://www.refworld.org. es/docid/5c92b8584.html

Vaca, D. R. (2017). Medidas cautelares constitucionales. Derecho Ecuador [Blog]. Recuperado de: https://www.derechoecuador.com/medidas-cautelares-constitucionales

Recibido: $15 / 01 / 2020$

Aprobado: 12/06/2020

Estefanía Samaniego Valencia: Investigadora jurídica independiente

Ciudad: Quito

País: Ecuador 
